REPRODUCTION

\title{
Response to Orr and Siegler-collective intentionality and procreative desires: the permissible view on consent to posthumous conception
}

\section{Parker}

J Med Ethics 2004;30:389-392. doi: 10.1136/jme.2002.002493

Orr and Siegler have recently defended a restrictive view concerning posthumous sperm retrieval and conception, which would limit insemination to those cases where the deceased man has provided explicit consent for such a procedure. The restrictive view dominates current law and practice. A permissible view, in contrast, would allow insemination and conception in all but those cases where the posthumous procedure has been explicitly refused, or where there is no reasonable evidence that the deceased person desired children. I describe a phenomenology of procreative desires which supports the permissible view, and which is compatible with requirements concerning the interests of the decedent, concepts of medical infertility, and the welfare of the future child. The account illustrates how our current obsession with individual rights and autonomy can be self-defeating and repressive.

\footnotetext{
Correspondence to:

M Parker, Mayne Medical

School, Herston Rd,

Herston, Queensland 4006, Australia; m.parker@uq.edu.au

Received

13 November 2002

In revised form

25 February 2003

Accepted for publication

17 March 2003
}

O rr and Siegler have recently outlined in this journal a restrictive view concerning posthumous semen retrieval and subsequent conception. ${ }^{1}$ They suggest three factors pertinent to the moral acceptability of posthumous retrieval-the welfare of the child to be, the question of respectful treatment of dead bodies, and the issue of consent-and they provide two illustrative cases.

\section{Case 1}

A young, recently separated man commits suicide, and his parents request sperm retrieval for the purposes of having a grandchild, claiming that their son would have wanted this, and that his estranged wife would be willing to have the child. A clinical ethics consultant advises against retrieval because there was no evidence that he would have wanted his widow to have his child.

\section{Case 2}

Another young man dies from multiorgan failure following pneumonia. His wife requests sperm retrieval to fulfil their long term wish for children, a desire supported by a recent infertility consultation. An ethics consultant agrees with the health team that retrieval is justified by the decedent's presumed wishes as presented through his wife's request.

The restrictive view is a general rejection of posthumous sperm retrieval and conception, except in cases where there is good evidence that the decedent would have wanted his widow qua widow to conceive and carry his child-that is, except in cases of explicit consent to posthumous conception. A more permissive view would allow retrieval in all cases, except where the decedent explicitly refused posthumous conception, or where there is good evidence that the decedent wished never to be a parent. Consent is a crucial factor in both views. To support the permissible view, I employ a phenomenology of the relationship between procreative desires and consent, which contrasts with the familiar, individualised conception employed by Orr and Siegler.

\section{THE WELFARE OF THE CHILD}

According to Orr and Siegler, the welfare of the child should be considered, even when explicit consent for posthumous conception is present, yet they provide no account of how posthumous conception might harm a child so conceived, and how this factor should qualify the acceptability of the procedure. They simply say that decisions about the welfare of the future child will vary depending on social circumstances and personal values. It is impossible to know how and to what extent they think this factor is influential, and it must be assumed that the issue of the welfare of the child is not crucial to their restrictive view.

However, others have suggested that the child's knowledge of his or her conception should be seen as supporting the restrictive view. For example, in a Queensland case in 2000 in which posthumous sperm retrieval was refused, Chesterman J said ${ }^{2}$ :

I cannot see how it can be said that the interests of [a child who has been conceived after the father's death] will be advanced by inevitable fatherlessness. The very nature of the conception may cause the child embarrassment or more serious emotional problems as it grows up. More significant, because the court can never know in what circumstances the child may be born and brought up, it is impossible to know what is in its best interests.

Against these speculative and somewhat circular concerns, I will later argue that the welfare of the future child is not threatened by posthumous conception, based on my alternative account of procreative desires and consent. 


\section{RESPECT FOR THE DEAD}

Orr and Siegler assert that while trespassing the integrity of a dead body, in order to benefit others, has been accepted by society, sperm retrieval from comatose or dead men has not, although they indicate that one third of 82 requests for retrieval in the USA in 1997 were honoured. They quote the view that sperm retrieval is "perilously close to rape", apparently in support of this general position, but without explication of this decidedly contentious claim. According to Orr and Siegler, there is a significant difference between giving consent for autopsy/organ retrievals and requesting sperm retrieval, in that the former is altruistically giving to benefit others, while the latter is taking for the benefit of the requester. In sperm retrieval without the donor's explicit consent, there is allegedly no consent at all, and the parents in case 1 and the wife in case 2 are making a request for their own benefit.

It sounds like Orr and Siegler consider that anyone who requests sperm retrieval should be treated, prima facie, as acting inappropriately because it is for their benefit, but no argument for this position is provided. However, taking something should only be considered impermissible if someone will thereby be harmed, and we are owed an account of the harms resulting from sperm retrieval. The requester will clearly not be harmed, nor, as I will argue below, will the donor, unless he had specifically, but unusually, rejected the idea of posthumous retrieval. Further, the requester will positively benefit from the retrieval, and so also, as I show, will the donor. Moreover, both donor and requester will benefit in a way which is additional to how they will benefit simply as individuals.

\section{INTERESTS AND EXPLICIT CONSENT: THE RESTRICTIVE VIEW}

Cases 1 and 2 identify the obvious stakeholders, including the decedents. While it is clear that once dead, a person may no longer be straightforwardly harmed, it is generally agreed that people retain interests which may be affected after their death. For example, a person's interests will be harmed by not observing the specific desires they had for their funeral, even though they are dead. Posthumous sperm retrieval arguably affects a deceased person's interests, because it changes the nature of the life of the deceased in this kind of way.

Ann Reichmann Schiff has argued that, without explicit consent, posthumous conception "deprives an individual of the opportunity to be the conclusive author of a highly significant chapter in his or her life".$^{3}$ According to this idea, we should be assured that our bodies will not be used in a manner which is inconsistent with our expectations, and posthumous conception should not be permitted in the absence of explicit consent, even if the deceased desired parenthood, since there is a big leap from the desire for parenthood to the assumption that a person would have wanted to become a posthumous parent. The desire for parenthood, of course, normally involves the desire to be an active parent; according to Schiff, unless explicit consent to be a deceased parent exists, the deceased is respected most by refusing to allow him to become such a parent. This approximates, as far as I can determine from their paper, Orr's and Siegler's restrictive view.

\section{TWO MORE CASES: THE UK AND AUSTRALIA}

Laws, guidelines, and the courts in the UK and Australia have also generally supported the restrictive view. When Diane Blood wanted to use sperm retrieved from her husband just prior to his death from meningitis, she was prevented from doing so by the Human Fertilisation and Embryology Act 1990 (UK), which permitted posthumous storage and use of sperm only in situations where the deceased husband had had adequate counselling at the time of semen donation, and had provided written consent. The sperm ought not have been stored, according to the Act, since he had not provided written consent, and it was stated that verbal or implied consent, even within the context of marriage, was no substitute for written consent. An important requirement of the Act was the direction against using the sperm unless the services are being provided for the woman and the man together, ${ }^{4}$ and the Court of Appeal determined that it is impossible to regard a dead person as being treated together with another. ${ }^{5}$

Although the legality of the initial removal of sperm from the deceased was not in dispute in this case, another issue arising is whether removal of sperm is consistent with the common law requirement that, in the absence of the capacity to consent, medical treatment must be in the patient's best interests. If a sperm donor is likely to die or remain in a persistent vegetative state, it has been argued that it stretches legal reasoning too far to think that the donor would benefit; rather, removal would result in a benefit to the recipient. ${ }^{6}$ Because the donor would not benefit in a conventional way, it is perceived that his interests are being ignored in favour of the self-interest of the person who can use his sperm. This approximates the giving/taking distinction identified by Orr and Siegler.

In the 1999 Victorian case of $A B \quad v$ Attorney General, concerning the removal and subsequent use of sperm from a recently deceased man at the urgent request of his widow, there was no statutory guidance at the time, and therefore no specific prohibition regarding the removal of sperm. However, the Infertility Treatment Act 1995 (Vic) prohibited the insemination of a woman with sperm from a man known to be dead. ${ }^{7}$ While it may have been possible to remove the stored sperm to another jurisdiction for the purposes of insemination, impediments also arose in the form of Australia's National Health and Medical Research Council Guidelines on Assisted Reproductive Technology, ${ }^{8}$ which describe as unethical the use of gametes or embryos harvested from cadavers. ${ }^{9}{ }^{10}$ Further barriers arose from the lack of evidence of medical infertility: common law ${ }^{11}$ has supported some Australian clinics' refusal of assisted reproductive treatment where evidence of medical infertility is lacking, and statutes in Victoria, South Australia, and Western Australia require such evidence for assisted reproductive treatment.

These cases demonstrate that a number of statutes and guidelines, and the common law have all exerted pressure against the ability of women to use the sperm of deceased partners to achieve a pregnancy in the UK and in Australian jurisdictions. There is an emphasis on the written consent of the deceased, and the impossibility of regarding a dead person as being treated together with another, or as helping to constitute a situation of medical infertility. Nevertheless, there was strong public support for Diane Blood's right to have donor insemination with her deceased husband's sperm, implying wider conceptions of the best interests of the deceased in these situations. After all, what weight should be attributed to the absence of an explicit desire to be a posthumous parent? While no one would prefer posthumous to active parenthood, many people clearly think that posthumous parenthood would be a good thing in circumstances which necessitate it.

The restrictive view would extinguish the satisfaction of a person's desire for parenthood because that desire does not explicitly imply a desire for posthumous parenthood. Is this justified? The desire to be a parent implies more than just the desire to be an active one. Each parent desires to advance his or her own lineage, to have a child with his or her partner, to 
create and experience the mystery of genetic integration with their partner, and so on. Removing the possibility of posthumous parenthood removes the satisfaction of an interest which is both more fundamental and more broad than the desire to actively parent, all in the name of not wanting to offend against the absence of a stated desire to be a posthumous parent. There seems to me to be no good reason to agree with Schiff that posthumous conception uses our bodies in a manner which is inconsistent with our expectations, as long as we are not overly literal and legalistic in conceiving what our expectations consist of. I submit that we respect deceased people better by allowing posthumous conception which satisfies their interests in parenthood, albeit posthumously.

So far my argument for a more permissible view has been in terms of individual interests. I now turn to my positive account of the relation between procreative desires and consent, which strengthens this view, caters for the requirements for medical infertility and co-treatment mentioned above, and is compatible with the welfare of the child to be.

\section{SEARLE ON COLLECTIVE INTENTIONALITY}

The mind has evolved to relate us to the environment and to others, and the relation between subjective states of the mind and the world is philosophically known as intentionality. Intentionality is a general term not restricted to intentions, interests, and desires but including them together with every other way in which the mind can be directed towards or be about the state of the world. ${ }^{12}$ John Searle has recently pointed to a prejudice about intentionality, which is the tendency to reduce "we-intentionality" to "I-intentionality", because we don't want to think of the former as irreducible on pain of having to postulate some sort of collective mental entity. ${ }^{13}{ }^{14}$ According to Searle, when we say "We intend to $\mathrm{x}^{\prime \prime}$, we usually analyse this as the conjunction of "I intend to $\mathrm{x}^{\prime \prime}$ and "I believe that you intend to $\mathrm{x}^{\prime \prime}$. On this conventional account, collective intentionality consists of individual intentionality and mutual belief.

Searle offers an alternative and simpler view: there is no reason to think that a single mind cannot contain collective

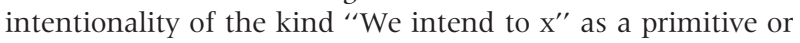
irreducible mental state. The prejudice is to think that because intentionality is a feature of individual minds, it has to be in the form of first person mental states. Searle uses his concept as a necessary part of his general explanation of social and institutional facts. The irreducibility of "weintentionality" does not reside in any collective mental entity from which we are derived and which directs us, but in the fact that some intentional states are simply of this kind. In the case where my friend and I intend to travel together to India, we can each describe our own and each other's distinct mental states as being of the form "We intend to travel to India".

\section{PROCREATIVE DESIRES AND CONSENT FOR POSTHUMOUS CONCEPTION}

The husbands of Diane Blood, $\mathrm{AB}$ and case 2 above all desired to have children, yet presumably did not desire specifically to become posthumous parents. On a first person conception, the desire to be a parent, along with all other desires, perishes when we die. But procreative desires, it seems to me, are better understood in terms of Searle's concept of collective intentionality: within the mind of each potential parent there exists the same primitive collective intention-"We desire to be parents". (Of course, some potential parents do not share such "we-desires": there are clearly cases where a person's desire for parenthood will be purely individual, with the contribution from the partner being regarded as no more than an instrumental, biological necessity. However, this does not change the nature of the central case I am describing.)

Any "we-desire" would survive the death of one partner, in the mind of the other, and the collective desire of the decedent is thereby carried into the future, since it is the same desire as that of the survivor. Collective intentionality supports posthumous conception, since as well as supporting the decedent's interest in parenthood expressed when he was alive, it shows that there remains a live desire which can be satisfied even though he is now dead. This challenges the idea that a request for posthumous retrieval brings about a split between the self-interest of the requesting partner and the interests of the decedent, and that requests are fundamentally about ethically questionable taking in order to benefit.

Schiff is right to claim that death does not obliterate interests, and that autonomy deserves protection after death. But being protected from something one never explicitly agreed to, viz posthumous parenthood, comes at the price of preventing both the individual desire for parenthood and the existing desire being fulfilled. Posthumous conception is the means by which this live and fundamental we-desire to be parents is satisfied.

The account also works against the idea that it is impossible to regard a dead person as being treated together with another. That idea also has as its background the assumption that all one's desires perish with one's bodily demise and prevents the physiologically fertile surviving woman from utilising infertility treatment. The claim that the widow of a deceased sperm donor cannot provide evidence of medical infertility loses coherence if we join the surviving "we-desire" with the inability of the husband to inseminate his partner. Seen thus, we have a straightforward case of male infertility which can be treated by sperm retrieval and artificial insemination.

How does the collective intentionality account deal with Orr's and Siegler's case 1? Here, the parents of the separated, depressed, and now dead man claim that their son would have wanted his ex-partner to conceive their child, and that she would have been willing to do this. In this case, we are not given the woman's view, but the collective intentionality account requires this for obvious reasons. If she rejects the view that they wanted a child, there is no case for retrieval, based not only on the collective intentionality account but also from the point of view of her current individual interests.

Another problem for the collective intentionality idea is presented by the woman who passes off her individual desire for children as a collective one, by claiming falsely that her deceased partner desired children. Here the ethical concerns are intertwined with empirical considerations. First, it is less likely that the partner of a deceased man who did not want children would want to proceed than in situations like case 2. Secondly, in case she did, there would often, perhaps usually, be evidence from others that he did not desire children, which could be called upon to inform decision makers. Third, we should balance the harm which would occur from such cases against that which would result from preventing those who desired children from having them, albeit posthumously. On the collective intentionality account, and given the empirical probabilities, the latter will outweigh the former.

Finally, what would the account say about a male survivor's request for posthumous egg retrieval from his deceased female partner? In principle, this case is symmetrical with the familiar one, and I see no distinction concerning the status of the surviving "we-desire". Procreation in this case, however, would require the further step of a surrogacy arrangement, in order to unite the retrieved egg with the survivor's sperm. This seems to be a 
distinct ethical and policy issue which is not affected one way or the other by the acceptance of collective intentionality.

\section{CHILD WELFARE AGAIN}

Even if Searle's account of collective intentionality is accepted, it might be thought unnecessary if the primary concern is to prevent harm to direct stakeholders. In cases such as Diane Blood, $\mathrm{AB}$ and case 2 above, where it was known that the deceased husband had desired a family, and no one could conceivably be harmed by posthumous insemination, what need is there to appeal to complexities concerning collective procreative desires? As I have said, one might argue simply that the absence of the explicit desire to be a posthumous parent is made to bear too much weight, and the onus ought to be on those who would prevent posthumous parenthood to show that it would have been explicitly rejected.

If harm to the future child demonstrably flowed from posthumous conception, however, such implied consent would be insufficient to deliver a permissible conclusion. Might harm occur by being knowingly denied access to one biological parent? ${ }^{3}$ Of course, it might be said that since there are many fatherless and/or motherless children, the state of being parentless itself should not impede posthumous procreation. But there are two distinguishable states of parentlessness-one as a result of some unforeseen event, and the other as a result of a deliberate decision on the part of somebody else that one be parentless. Now, we can only speculate that a child would be harmed in this latter situation, and there is only one way to empirically test whether harm would occur. But if collective intentionality correctly describes procreative desires, the child who is born, knowing why actual contact with her biological father was never possible, may well enjoy a special, positive relationship with her father, through the survival in her mother, and its actualisation, of her father's collective desire to bring her into existence. While it makes no sense to wonder what a potential child would think of having been prevented from ever being born, a posthumously conceived child may well consider that it would have been wrong for her mother to have been prevented from conceiving her, both from her own and her father's point of view.

Another of Orr's and Siegler's hesitations was over whether the deceased man would want his wife to be a single mother and what his views were concerning the wellbeing of a child raised by a single parent. In case 2, they would not allow posthumous sperm retrieval and conception, not only because of the distinction between the desire for parenthood and the desire for posthumous parenthood, but also because of their claim that "her own self-interest could have clouded her understanding of what his wishes would have been in circumstances that he never discussed and probably never contemplated". ${ }^{15}$ I have already challenged the notion of selfinterest which is employed here. Especially given that this couple had attended for infertility treatment, the conclusion offered seems offensive.

In the most recent Queensland case, Muir J opined similarly, and speculatively, as follows ${ }^{16}$ :

Had he turned his mind to the question, he would no doubt have given anxious consideration to the best interests of the applicant and the child or children to be born as a result of the proposed procedure. He would have seen that the existence of such a child or children was capable of restricting the applicant's ability to pass beyond her grief and start life afresh. He would have contemplated also the difficulties which face a single working mother and the constraints that would be imposed on her working life and on her ability to enter into a new relationship or relationships.

This case was one where the deceased man had been enthusiastic about starting a family. Such a speculative splitting of both potential parents' desires is unwarranted, as are the implications of this judgment and Orr's and Siegler's view concerning the surviving women's competence.

\section{INDIVIDUAL AND COLLECTIVE RIGHTS}

These prejudices concerning self-interest also illustrate just how obsessed we have become with rights conceived exclusively as owned by individuals. To conceptualise the considerations as being those of her self-interest and his wishes splits these two people apart, as his death could never do. Much of our law, especially that related to human health, disease, and reproduction, has been developed within a framework of autonomy and individual rights. ${ }^{17}$ In the case of posthumous conception, this narrow conception can abridge both the individual and collective desires of both the widow and the deceased sperm donor. There may be other cases where collective intentionality and correlative rights could be considered alongside our conventionally privileged individual rights. Consider decisions to withhold or withdraw life sustaining treatment. Surrogate decision making aims to preserve the authenticity and practical effect of the incompetent individual's desires. But the collective state described by "We don't want this treatment to continue" may preserve those rights as authentically as "He would not have wanted this treatment to continue". Collective desires may help make more complete sense of some of these kinds of situations. First person preferences and rights are privileged in our culture and our law. We should recognise, individually and collectively, the reality of collective desires and intentions, and further explore their ethical, social, and policy implications.

\section{REFERENCES}

1 Orr RD, Siegler M. Is posthumous semen retrieval ethically permissible? J Med Ethics 2002;28:299-303.

2 In the matter of Gray [2000] QSC 390 (12 October 2000), para 23.

3 Schiff AR. Posthumous conception and the need for consent. Med J Aust 1999; 170:53-4.

4 Human Fertilisation and Embryology Act 1990 (UK) s4 (1) (b)

5 R v Human Fertilisation and Embryology Authority, ex parte Blood [1997] 2 All ER 687.

6 Rogers ME. Gametes: storage, consent and treatment. Web J Curr Legal Issues, 1997;3. Available at webjcli.ncl.ac.uk/1997/issue3/rodgers3.html (accessed on 7 July 2002).

7 Infertility Treatment Act 1995 (Vic) s43 (a)

8 Ethical Guidelines on Assisted Reproductive Technology. Available at www.health.gov.au/nhmrc/publications/synopses/e28syn.htm (accessed on 7 July 2002).

9 Otlowski M. AB v Attorney-General (Vic). J Law Med, 1999;6:228.

10 The recently released draft revision of the Guidelines retains the proscription against sperm retrieval: section 10.13 says "Gametes should not be obtained from cadavers for use in reproductive technology programs". Available at www.health.gov.au/nhmrc/issues/index.htm (accessed on 10 July 2002).

11 JM v QFG (unreported, No BC9804065, Queensland Court of Appeal, Davies, Pincus, and Thomas JJA).

12 Searle J. Mind, Language and Society. London: Weidenfeld and Nicolson, 1999:85.

13 See reference 12: 118-21

14 Searle J. The Construction of Social Reality. London: Penguin, 1995:23-6.

15 See reference 1: 302.

16 Baker v State of Queensland [2003] QSC 002 (03/39); judgment available at www.courts.qld.gov.au/qjudgment/QSC\%202003/QSC03-002.pdf (accessed on 21 January 2003).

17 van der Burg W. Bioethics and law: a developmental perspective. Bioethics 1997;11:91-114. 